\title{
Equilibrium Studies on Interaction of Organotin (IV) Moieties with N-O Donor Ligands
}

\author{
Pratibha Paliwal (Bhatele) ${ }^{1}$, Seema Yadav (Kumari) ${ }^{2}$ \\ ${ }^{1}$ Department of Science, Kamla Nehru College for Women, Phagwara, Punjab, India \\ ${ }^{2}$ School of Studies in Chemistry, Jiwaji University, Gwalior, M.P, India
}

\begin{abstract}
Equilibrium studies of dioctyltin [DOT] (IV) and dimethyltin [DMT] (IV) Moieties with nitrogen and oxygen donor ligands i.e. glycine and alanine are investigated potentiometrically. Experiments are carried out in $10 \%$ alcohol medium at three different temperatures $\left(20 \pm 1^{\circ} \mathrm{C}, 30 \pm 1^{\circ} \mathrm{C}\right.$ and $\left.40 \pm 1^{\circ} \mathrm{C}\right)$ and at three ionic strengths $(\mu=0.05 \mathrm{M}, 0.10 \mathrm{M}$ and $0.15 \mathrm{M})$. The experimental data are subjected to computational analysis and thermodynamic parameters $\left(\Delta G^{\circ}, \Delta H^{\circ}\right.$ and $\left.\Delta S^{\circ}\right)$ for non protonated, monohydroxo and dihydroxo species have been calculated. The concentration distribution of the various complex species in solution has been evaluated as a function of $\mathrm{pH}$ and is presented in the form of speciation curves with the help of SCOGS computer program.
\end{abstract}

Keywords: Pontentiometry, Organotin (IV), SCOGS, Thermodynamic parameters, Speciation Curves.

\section{Introduction}

Organotin compounds have emerged as potential future pharmaceuticals as antitumour agents in place of platinum antitumour drugs [1]-[4]. Thus, in order to get a better insight in how the organotin species behave inside the biological systems, it is necessary to explore their coordination chemical behaviour towards biomolecules that occur in the biological medium. Further, organotin (IV) compounds are widely distributed in environment owing to their intensive production for several industrial applications, e.g. as fungicides and acaricides in agriculture, as wood and stone preservatives, as stabilizers and catalysts in PVC and in foam production [5]-[8], and as antifouling additives in paints for ships [9]. In natural waters they can originate also from bio-alkylation processes [10].

In view of this, the studies based on interaction of organotin (IV) moieties with wide range of ligands becomes highly significant. Considerable efforts have been made to understand the binding mode of organotin compounds with biologically relevant ligands such as amino acids [11]-[14] and dipeptides [15], [16] which constitute a very important class of biomolecules.

Shoukry and his group of researchers published papers based on equilibrium studies of diorganotin (IV) moieties with amino acids and some selected ligands of biological importance [17]-[20].

It has been observed that most of the work is done in solid state and solution equilibrium studies have been less focused, which could provide essential information on the biospeciation of organotin moiety and thus on its bioavailability. The present communication describes the results of equilibrium studies on organotin (IV) moieties with nitrogen and oxygen donor ligands.

\section{Experimental Details}

\subsection{Materials and reagents}

All the chemicals used were of analytical grade and the solutions of ligands were prepared in doubly distilled $\mathrm{CO}_{2}$ free water. DMT (IV) and DOT (IV) metal were prepared by dissolving their accurate weighed amounts in ethanol.

\subsection{Equipments and Measuring Techniques}

An Elico digital pH-meter model LI-127 with ATC probe and combined electrode type (CL-51B-Glass body; range 0$14 \mathrm{pH}$ unit; $0-100^{\circ} \mathrm{c}$ automatic/manual) with accuracy \pm 0.01 was used for $\mathrm{pH}$ measurement. The $\mathrm{pH}$ meter was calibrated with aqueous buffers ( $\mathrm{pH} 4.0$ and 9.20) before and after titration.

Following sets of titration mixture were prepared with the ratio of $10 \%$ alcohol and $90 \%$ water by keeping total volume $50 \mathrm{~mL}$ and titrated against $0.10 \mathrm{M} \mathrm{NaOH}$ solution, ionic strengths $(\mu=0.05,0.10,0.15 \mathrm{M})$ is maintained by adding different concentration of $\mathrm{NaNO}_{3}$ solution to each titration mixture at temperature $20 \pm 1^{\circ} \mathrm{C}, 30 \pm 1^{\circ} \mathrm{C}$ and $40 \pm 1^{\circ} \mathrm{C}$.

The complex of each titration mixtures is as follows:-

1. Mixture $1:-\mathrm{HNO}_{3}\left(2.0 \times 10^{-3} \mathrm{M}\right)$ (Acid titration)

2. Mixture 2 :- $\mathrm{HNO}_{3}\left(2.0 \times 10^{-3} \mathrm{M}\right)+$ ligand $\left(1.0 \times 10^{-3} \mathrm{M}\right)$ (Ligand titration)

3. Mixture $3:-\mathrm{HNO}_{3}\left(2.0 \times 10^{-3} \mathrm{M}\right)+$ ligand $\left(1.0 \times 10^{-3} \mathrm{M}\right)$

$+\operatorname{Metal}\left(1.0 \times 10^{-3} \mathrm{M}\right)$

(Metal : Ligand (1:1) titration)

\section{Results and Discussion}

\subsection{Titration Curves}

As a result of titration of set of three mixtures (1, 2 and 3) three titration curves were obtained for each system. These curves are presented in figures 1 and 2 as a plot of $\mathrm{pH}$ vs ' $a$ ' where $a=$ moles of alkali per mole of metal/ligand. 


\section{International Journal of Science and Research (IJSR) \\ ISSN (Online): 2319-7064}

Index Copernicus Value (2013): 6.14 | Impact Factor (2014): 5.611

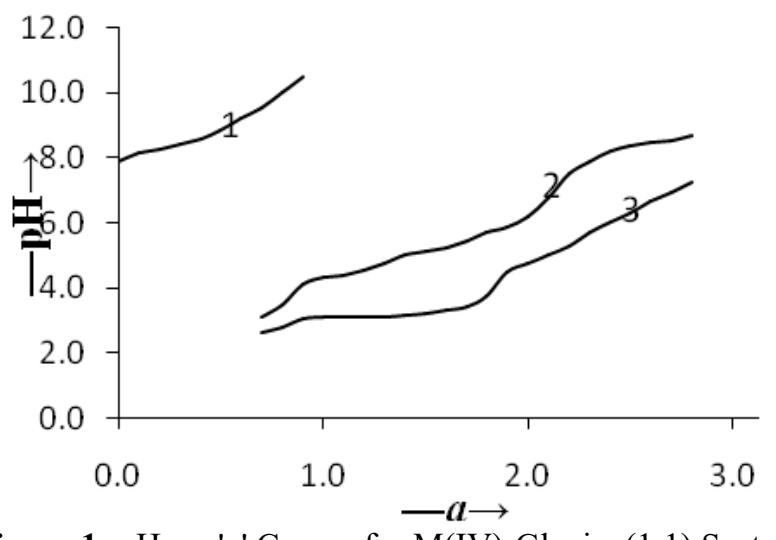

Figure 1: pH vs. ' $a$ ' Curves for M(IV)-Glycine(1:1) System at $30 \pm 1{ }^{\circ} \mathrm{C}\left[\mu=0.10 \mathrm{M}\left(\mathrm{NaNO}_{3}\right)\right]$

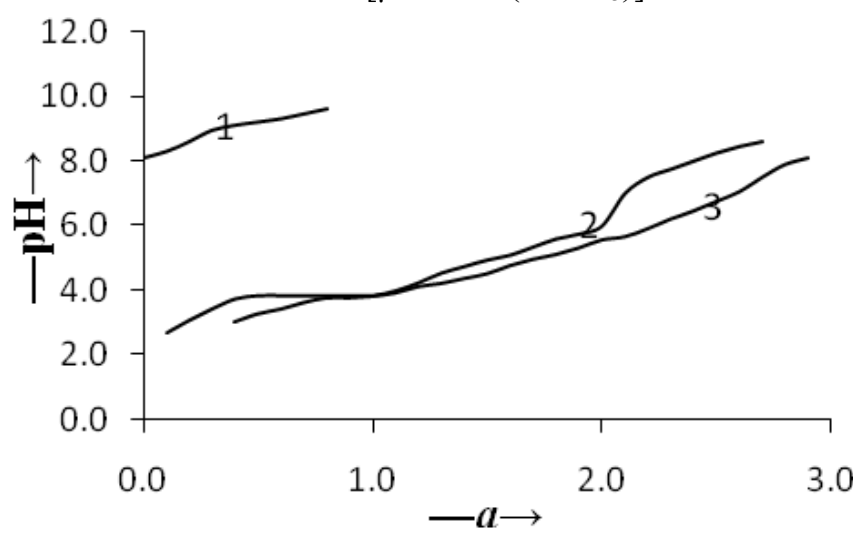

Figure 2: $\mathrm{pH}$ vs. ' $a$ ' Curves for M(IV)-Alanine(1:1) System at $30 \pm 1{ }^{\circ} \mathrm{C}\left[\mu=0.10 \mathrm{M}\left(\mathrm{NaNO}_{3}\right)\right]$

Curve 1- Ligand titration curve

Curve 2- DMT (IV)-ligand titration curve

Curve 3- DOT (IV)-ligand titration curve

Figures 1and 2 depict the interaction of DMT(IV)/DOT(IV) with glycine and alanine respectively. The observations lead to the conclusion that the proton dissociate in higher $\mathrm{pH}$ range ( $\mathrm{pH} \approx 8.0$ ) thereby indicating strong basic nature of ligands. The values of dissociation constants obtained agree well with the literature values [21].

Curves 2 and 3 in figures 1 and 2 depicting the titration of DMT (IV)-ligand / DOT (IV)-ligand respectively, show the right hand shift from the ligand titration curve 1, thereby suggesting the formation of metal-ligand complex in the $\mathrm{pH}$ ranging from $2.5-3.8$. Further a weak inflection at $a=2$ is observed in these systems, can be attributed to the formation of ML species by the deprotonation of MLH complex. This is followed by sharp inflections observed at $a=2(\mathrm{pH} \approx 5.0)$ and $a=3(\mathrm{pH} \approx 7.0)$ indicating the formation of monohydroxy $\mathrm{ML}(\mathrm{OH})$ and dihydroxy $\mathrm{ML}(\mathrm{OH})_{2}$ species respectively.

These equilibria can be represented as follows:

$$
\begin{aligned}
& 0 \leq a \leq 1 \\
& \mathrm{M}+\mathrm{L} \\
& \rightleftharpoons \mathrm{ML} \\
& -1.0 \\
& \mathrm{ML}+\mathrm{OH} \\
& 2 \leq a \leq 3 \\
& \rightleftharpoons \quad \mathrm{ML}(\mathrm{OH}) \\
& 3 \leq a \leq 4 \\
& \mathrm{ML}(\mathrm{OH})+\mathrm{OH} \rightleftharpoons \mathrm{ML}(\mathrm{OH})_{2} \quad \ldots-1.2
\end{aligned}
$$

Algebraic method of Martell and Chaberek as modified by Dey et al. has been applied to calculate the values of equilibrium constants [22]-[25].

The values of protonation constants for various ligands and the formation constants of metal-ligand complexes are tabulated in tables 1-3. These tables also include the values of equilibrium constants obtained for hydroxo species.

From these tables the formation of ML species is well evidenced by significantly high values of $\log \mathrm{K}_{\mathrm{ML}}^{\mathrm{M}}$. However the major species in the investigated equilibria are hydroxo species which can be understood by the higher values of log $\mathrm{K}_{\mathrm{ML}(\mathrm{OH})}^{\mathrm{ML}}$ and $\log \mathrm{K}_{\mathrm{ML}(\mathrm{OH}) 2}^{\mathrm{MIL} \text {. }}$

The values of equilibrium constants for various protonligand and metal-ligand systems were refined by applying the computer programme SCOGS [26]-[28]. These data were used to obtain the speciation curves. Analysis of these curves is discussed here under :

\subsection{Organotin (IV)-Glycine / Alanine Systems ( figures 3 and 6 and tables 2 and 3 )}

The nature of curves observed in the above refered figures suggest that in case of DMT (IV)-glycine / alanine system (figures 3 and 5) the concentration of free metal is quite low $(20 \%)$ (curve 1) and the formation of ML species (curve 2) occurs from the initial $\mathrm{pH}$ and the reaches the maximum at $\mathrm{pH} \approx 4.0$. The concentration of ML species is significantly high $(\$ 90 \%)$. Above pH $\$ 5.0$ hydroxo complex exists as predominant species. In case of DOT (IV)-glycine / alanine system (figures 4 and 6) the concentration of free metal is high (approx.80\%) as evidenced by curve 1 and the formation of ML species is evidenced at $\mathrm{pH}>4.1$ (curve 2). The percentage formation of ML species is about $50 \%$ which is low as compared to that observed in case of DMT (IV)-glycine system. This can be attributed to the steric crowding due to bulky nature of DOT (IV) cation . Above $\mathrm{pH} 4.5$ the formation of hydroxo complex is evidenced as the major species (curves 3,4 in figures 5 and 6).

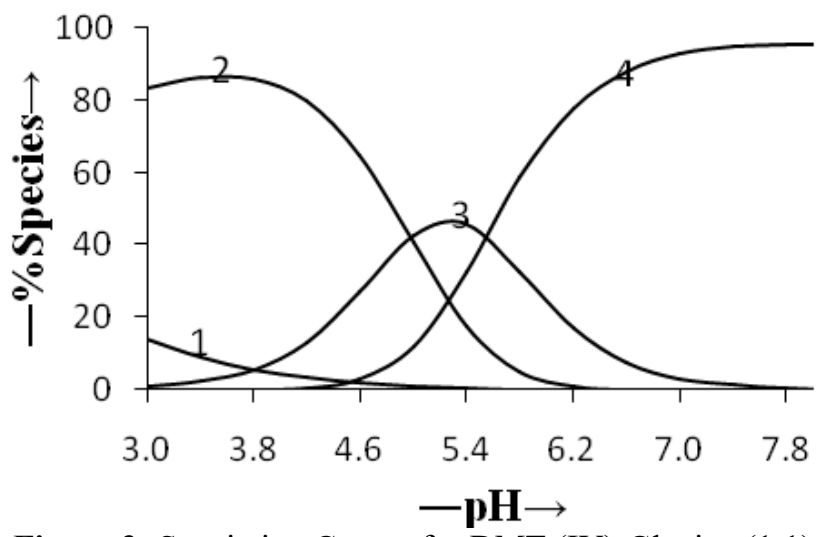

Figure 3: Speciation Curves for DMT (IV)-Glycine (1:1) System at $30 \pm 1^{\circ} \mathrm{C}\left[\mu=0.10 \mathrm{M}\left(\mathrm{NaNO}_{3}\right)\right]$

(Charges have been omitted for the sake of simplicity). 


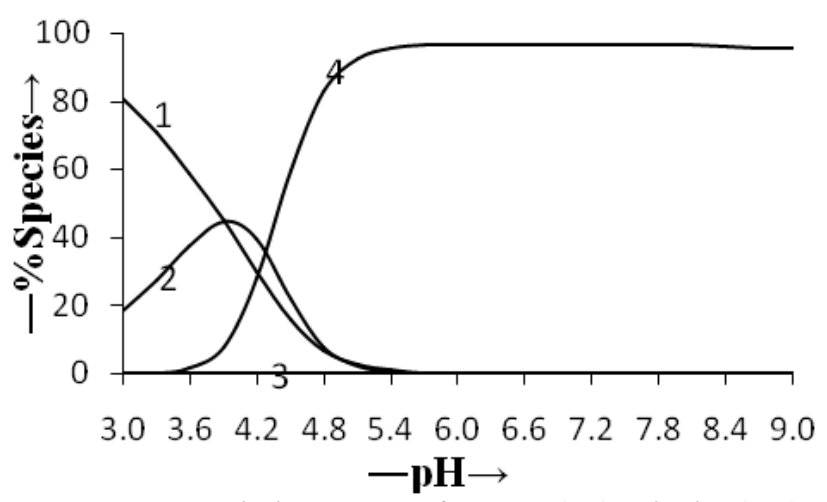

Figure 4: Speciation Curves for DOT(IV)-Glycine(1:1) System at $30 \pm 1^{\circ} \mathrm{C}\left[\mu=0.10 \mathrm{M}\left(\mathrm{NaNO}_{3}\right)\right]$

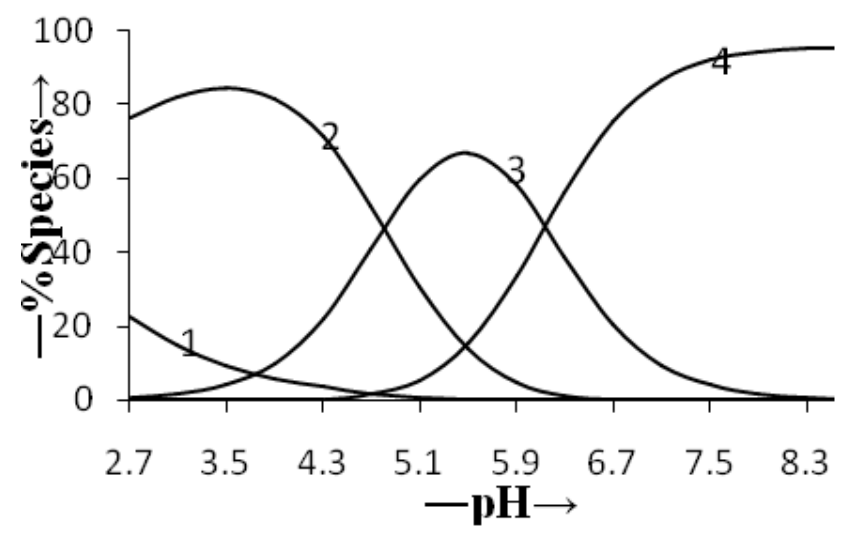

Figure 5: Speciation Curves for DMT (IV)-Alanine (1:1) System at $30 \pm 1^{\circ} \mathrm{C}\left[\mu=0.10 \mathrm{M}\left(\mathrm{NaNO}_{3}\right)\right]$

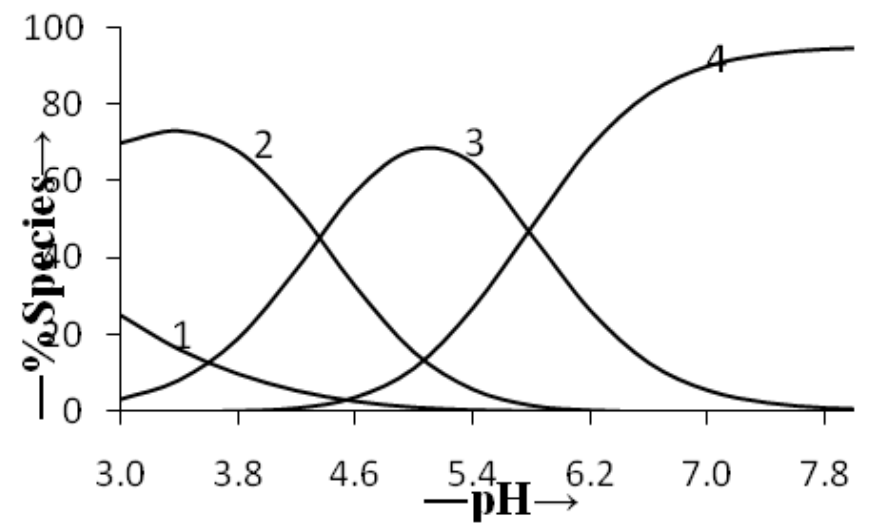

Figure 6: Speciation Curves for DOT(IV)-Alanine (1:1) System at $30 \pm 1^{\circ} \mathrm{C}\left[\mu=0.10 \mathrm{M}\left(\mathrm{NaNO}_{3}\right)\right]$
Where,

Curve $1:[\mathrm{M}] ; 2:[\mathrm{ML}] ; 3:[\mathrm{ML}(\mathrm{OH})] ; 4:\left[\mathrm{ML}(\mathrm{OH})_{2}\right]$

The values of the thermodynamic stability constant $\mathrm{K}_{\mu \rightarrow 0}$, are used to determine the standard free energy change $\left(\Delta \mathrm{G}^{\circ}\right)$ for the complexation reaction from Van't Hoff isotherm :

$\Delta \mathrm{G}^{\circ}=-2.303 \mathrm{RT} \ln \mathrm{K}_{\mu \rightarrow 0}$

The Gibb's Helmholtz equation is :

$\Delta \mathrm{G}^{\circ}=\Delta \mathrm{H}^{\circ}-\mathrm{T} \Delta \mathrm{S}^{\circ}$

From 1.3 and 1.4

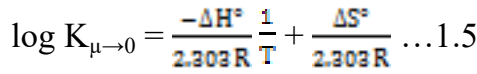

\section{Conclusion}

The results observed in case of organotin (IV) cation with amino acids is perhaps due to the preferable binding of dialkyltin (IV) cation with nitrogen as compared to oxygen (17). However, this prediction needs further support by spectroscopic studies. Complex formation is more prefered with alanine as compared to glycine. This is in accordance with the earlier reported results (29).

On observing the values recorded in tables 2 and 3 it is observed that complex formation decrease with increasing ionic strength and increasing temperature.It is seen that $\Delta \mathrm{G}^{\circ}$ decrease with increase in temperature. Negative value of $\Delta \mathrm{H}^{\circ}$ and positive value of $\Delta \mathrm{S}^{\circ}$ supports the favourable conditions for complex formation and it indicates that the reaction is exothermic in nature.

\section{Acknowledgement}

The authors are highly thankful to Prof. K.Dwivedi, Prof. S.K. Srivastava, Department of Chemistry, Jiwaji University (M.P.) and Prof. Renu Nair (Ahuja), V.R.G. Girls P.G. College Morar for his/her valuable support.

Table 1: Protonation Constant of Ligands at different Temperatures and Ionic Strengths

\begin{tabular}{|c|c|c|c|c|c|c|c|c|c|c|c|c|}
\hline \multirow{2}{*}{ Parameters } & \multicolumn{4}{|c|}{$20^{\circ} \mathrm{C}$} & \multicolumn{4}{|c|}{$30^{\circ} \mathrm{C}$} & \multicolumn{4}{|c|}{$40^{\circ} \mathrm{C}$} \\
\hline & $0.05 \mathrm{M}$ & $0.10 \mathrm{M}$ & $0.15 \mathrm{M}$ & $\mu \rightarrow 0$ & $0.05 \mathrm{M}$ & $0.10 \mathrm{M}$ & $0.15 \mathrm{M}$ & $\mu \rightarrow 0$ & $0.05 \mathrm{M}$ & $0.10 \mathrm{M}$ & $0.15 \mathrm{M}$ & $\mu \rightarrow 0$ \\
\hline \multicolumn{13}{|c|}{ Glycine } \\
\hline $\log \beta_{\text {सIL. }}$ & 9.01 & 8.87 & 8.80 & 9.40 & 8.77 & 8.74 & 8.60 & 9.08 & 8.56 & 8.40 & 8.30 & 9.00 \\
\hline \multicolumn{13}{|c|}{ Alanine } \\
\hline $\log \beta_{\text {सम. }}$ & 9.20 & 9.04 & 8.84 & 9.55 & 8.84 & 8.82 & 8.80 & 8.95 & 8.21 & 8.18 & 8.14 & 8.50 \\
\hline
\end{tabular}




\section{International Journal of Science and Research (IJSR) \\ ISSN (Online): 2319-7064}

Index Copernicus Value (2013): 6.14 | Impact Factor (2014): 5.611

Table 2: Thermodynamic Parameters of M (IV)- Glycine Systems DMT(IV)-Glycine System

\begin{tabular}{|c|c|c|c|c|c|c|c|c|}
\hline \multirow[b]{2}{*}{ Parameter } & \multicolumn{2}{|c|}{$20^{\circ} \mathrm{C}$} & \multicolumn{2}{|c|}{$30^{\circ} \mathrm{C}$} & \multicolumn{2}{|c|}{$40^{\circ} \mathrm{C}$} & \multirow{2}{*}{$\begin{array}{c}-\Delta \mathrm{H}^{\circ} \\
\mathrm{kJmol}^{-} \\
1\end{array}$} & \multirow{2}{*}{$\begin{array}{c}\Delta \mathrm{S}^{\circ} \\
\mathrm{JK}^{-} \\
{ }^{1} \mathrm{~mol}^{-1}\end{array}$} \\
\hline & $\log K_{\mu \rightarrow 0}$ & $\begin{array}{c}-\Delta \mathrm{G}^{\circ} \\
\mathrm{k} \mathrm{H} \mathrm{Jmol}^{-1}\end{array}$ & $\log K_{\mu \rightarrow 0}$ & $\begin{array}{c}-\Delta \mathrm{G}^{\circ} \\
\mathrm{l}=\mathrm{Jm} \mathrm{mol}^{-1}\end{array}$ & $\log K_{\mu \rightarrow 0}$ & $\begin{array}{c}-\Delta \mathrm{G}^{\circ} \\
\mathrm{l}=\mathrm{Jmol}^{-1}\end{array}$ & & \\
\hline $\log K_{3 L}^{\mathrm{H}}$ & 9.00 & 50.49 & 8.90 & 51.63 & 8.80 & 52.74 & 19.15 & 107.22 \\
\hline $\log \mathrm{K}_{\mathrm{s!}(\mathrm{OH})}^{\mathrm{sL}}$ & 12.20 & 68.44 & 11.80 & 68.46 & 11.81 & 70.78 & 37.34 & 105.34 \\
\hline $\log K_{3 \pi(\mathrm{OH}) 2}^{\mathrm{su}(\mathrm{OH})}$ & 14.20 & 79.66 & 14.15 & 82.09 & 14.10 & 84.50 & 9.57 & 239.33 \\
\hline \multicolumn{9}{|c|}{ DOT(IV)-Glycine System } \\
\hline \multirow[b]{2}{*}{ Parameter } & \multicolumn{2}{|c|}{$20^{\circ} \mathrm{C}$} & \multicolumn{2}{|c|}{$30^{\circ} \mathrm{C}$} & \multicolumn{2}{|c|}{$40^{\circ} \mathrm{C}$} & \multirow{2}{*}{$\begin{array}{c}-\Delta \mathrm{H}^{\circ} \\
\mathbf{k J m o l}^{-} \\
1\end{array}$} & \multirow{2}{*}{$\begin{array}{c}\Delta \mathrm{S}^{\circ} \\
\mathrm{JK}^{-} \\
\mathrm{mol}^{-1}\end{array}$} \\
\hline & $\log K_{\mu \rightarrow 0}$ & $\begin{array}{c}-\Delta \mathrm{G}^{\circ} \\
\mathrm{k} \mathrm{H} \mathrm{Jmol}^{-1}\end{array}$ & $\log \mathrm{K}_{\mu \rightarrow 0}$ & $\begin{array}{c}-\Delta \mathrm{G}^{\circ} \\
\mathrm{k}=\mathrm{Jmol} \mathrm{l}^{-1}\end{array}$ & $\log \mathrm{K}_{\mu \rightarrow 0}$ & $\begin{array}{c}-\Delta \mathrm{G}^{\circ} \\
\mathrm{l} \mathrm{k} \mathrm{Jmol}^{-1}\end{array}$ & & \\
\hline $\log \mathrm{K}_{\mathrm{sL}}^{\mathrm{s}}$ & 9.55 & 53.58 & 9.50 & 55.12 & 9.52 & 57.05 & 2.87 & 172.87 \\
\hline $\log \mathrm{K}_{3 \mathrm{~L}(\mathrm{OH})}^{\mathrm{sL}}$ & 12.30 & 69.00 & 11.75 & 68.17 & 11.70 & 70.12 & 57.44 & 38.61 \\
\hline $\log K_{3 \pi(\mathrm{OH}) 2}^{\mathrm{sa}(\mathrm{OH})}$ & 15.20 & 85.27 & 14.85 & 86.15 & 14.80 & 88.70 & 38.29 & 159.88 \\
\hline
\end{tabular}

Table 3: Thermodynamic Parameters of M (IV)- Alanine Systems

DMT(IV)- Alanine System

\begin{tabular}{|c|c|c|c|c|c|c|c|c|}
\hline \multirow[b]{2}{*}{ Parameter } & \multicolumn{2}{|c|}{$20^{\circ} \mathrm{C}$} & \multicolumn{2}{|c|}{$30^{\circ} \mathrm{C}$} & \multicolumn{2}{|c|}{$40^{\circ} \mathrm{C}$} & \multirow{2}{*}{$\begin{array}{c}-\Delta \mathrm{H}^{\circ} \\
\mathbf{k J m o l} \\
1\end{array}$} & \multirow{2}{*}{$\begin{array}{c}\Delta \mathrm{S}^{\circ} \\
\mathrm{JK}^{-} \\
{ }^{1} \mathrm{~mol}^{-1}\end{array}$} \\
\hline & $\log \mathrm{K}_{\mu \rightarrow 0}$ & $\begin{array}{c}-\Delta \mathrm{G}^{\circ} \\
\mathrm{k} \in \mathrm{J} m \mathrm{ol}^{-1}\end{array}$ & $\log K_{\mu \rightarrow 0}$ & $\begin{array}{c}-\Delta \mathrm{G}^{\circ} \\
\mathrm{k} \mathrm{E} \mathrm{mmol}^{-1}\end{array}$ & $\log K_{\mu \rightarrow 0}$ & $\begin{array}{c}-\Delta \mathrm{G}^{\circ} \\
\mathrm{k} \mathrm{km} \mathrm{l}^{-1}\end{array}$ & & \\
\hline $\log K_{M I}^{M}$ & 9.30 & 52.17 & 9.10 & 52.79 & 9.00 & 53.94 & 28.70 & 80.09 \\
\hline $\log \mathrm{K}_{\mathrm{ML}}^{\mathrm{ML}}(\mathrm{OH})$ & 12.00 & 67.32 & 11.75 & 68.17 & 11.70 & 70.12 & 28.72 & 131.50 \\
\hline $\log \mathrm{K}_{\mathrm{ML}(\mathrm{OH}) 2}^{\mathrm{ML}(\mathrm{OH})}$ & 14.70 & 82.47 & 14.35 & 83.25 & 14.34 & 85.94 & 34.46 & 163.20 \\
\hline \multicolumn{9}{|c|}{ DOT(IV)-Alanine System } \\
\hline \multirow[b]{2}{*}{ Parameter } & \multicolumn{2}{|c|}{$20^{\circ} \mathrm{C}$} & \multicolumn{2}{|c|}{$30^{\circ} \mathrm{C}$} & \multicolumn{2}{|c|}{$40^{\circ} \mathrm{C}$} & \multirow{2}{*}{$\begin{array}{c}-\Delta \mathrm{H}^{\circ} \\
\mathrm{kJmol} \\
1\end{array}$} & \multirow{2}{*}{$\begin{array}{c}\Delta \mathrm{S}^{\circ} \\
\mathrm{JK}^{-} \\
{ }^{1} \mathrm{~mol}^{-1}\end{array}$} \\
\hline & $\log \mathrm{K}_{\mu \rightarrow 0}$ & $\begin{array}{c}-\Delta \mathrm{G}^{\circ} \\
\mathrm{l} \mathrm{J} m \mathrm{ol}^{-1}\end{array}$ & $\log K_{\mu \rightarrow 0}$ & $\begin{array}{c}-\Delta \mathrm{G}^{\circ} \\
\mathrm{l}_{\mathrm{kJmol}} \mathrm{I}^{-1}\end{array}$ & $\log \mathrm{K}_{\mu \rightarrow 0}$ & $\begin{array}{c}-\Delta \mathrm{G}^{\circ} \\
\mathrm{l} \mathrm{kJmol}\end{array}$ & & \\
\hline $\log \mathrm{K}_{\mathrm{ML}}^{\mathrm{M}}$ & 10.00 & 56.10 & 9.65 & 56.08 & 9.60 & 57.53 & 38.29 & 60.31 \\
\hline $\log \mathrm{K}_{\mathrm{ML}}^{\mathrm{ML}}(\mathrm{OH})$ & 13.10 & 73.49 & 12.65 & 73.40 & 12.60 & 75.51 & 47.87 & 86.80 \\
\hline $\log \mathrm{K}_{\mathrm{ML}(\mathrm{OH}) 2}^{\mathrm{ML}(\mathrm{OH})}$ & 15.60 & 87.52 & 15.65 & 90.79 & 15.55 & 93.19 & 4.79 & 282.89 \\
\hline
\end{tabular}

\section{References}

[1] M. Nath, S. Pokharia and R. Yadav, Coord. Chem. Rev., 215, 99- 149, 2001.

[2] L. Pellerito and L. Nagy, Coord. Chem. Rev., 224, 111150, 2002.

[3] M. Gielen, Coord. Chem. Rev., 151, 41-51, 1996, .

[4] M. Gielen, Appl. Organomet. Chem., 16(9) 481-494, 2002.
[5] S.J. Blunden, P.A. Cusack and R. Hill, The Industrial Use of Tin Chemicals, Royal Society Chemistry, London, 1985.

[6] M.A. Champ and P.P. Saligman, Organotin: Environmental Fate and Effects,Chapman and Hall, London, 1996.

[7] J.J. Zuckerman, R.P. Reisdorf, H.V. Ellis and R.R. Wilkinson, Organometals and Organometalloids: Occurrence Fate in the Environment, F.E. Brinckan and J.M. Bellama (Ed.), (ACS Symp, Washington), Series No.82, 1978.

\section{Volume 4 Issue 12, December 2015}




\section{International Journal of Science and Research (IJSR) \\ ISSN (Online): 2319-7064}

Index Copernicus Value (2013): 6.14 | Impact Factor (2014): 5.611

[8] S.J. Blunden and A. Chapman, Organometallic Compounds in Environment, P.J. Craig (Ed.), Longman, Harlow, Essex, England, 1986.

[9] S.J. De Mora (Ed.), Tributyltin: Case History of an Environmental Contaminant, Cambridge Univ. Press, Cambridge, 1996.

[10] J.S. Thayer, in: H. Sigel and A. Sigel (Ed.), Metals Ions in Biological Systems,Vol.29, Marcel Dekker, Basel, 1993.

[11] M.J. Clarke, F. Zhu and D.R. Frasca, Chemical Rev., 99(9), 2511-2533, 1999.

[12] S.E. Castillo-Blum and N. Barba-Behrens, Coord. Chem. Rev., 196(1), 3-30, 2000.

[13] Meena Devi, Renu Nair (Ahuja), Jyotsna Gupta and K.Dwivedi, IQSR J. of Appl. Chem., 8(3), 52-58, 2015.

[14] Meena Devi, Renu Nair (Ahuja), and K.Dwivedi, Int. J. Theoretical and Applied Sci., 6(1), 154-163, 2014.

[15] M. Nath, H. Singh, P. kumar, A. Kumar, X. Song and G. Eng, Appl. Organomet. Chem., 23(9), 347-358, 2009.

[16] M. Nath, H. Singh, G. Eng and X.Song, J. Organomet. Chem., 693(15), 2541- 2550, 2008.

[17] M.M. Shoukry, Bull. Soc. Chim. Fr., 130, 117-120, 1993.

[18] M.M. Shoukry, Talanta, 43, 177-183, 1996.

[19] M.M. Shoukry and S.M. El-Medani, Collection of Czechoslovak Chemical Communications, 62(7) 10231028, 1997.

[20] M.M. Shoukry and M.M.H. Mohamed, Main Group Met. Chem., 20, 2011.

[21]D.D. Perrin, Stability Constants of Metal-Ion Complexes: Part B, Organic Ligands, Pergamon Press, Oxford, 1979.

[22] S. Chaberek and A.E. Martell, J. Am. Chem. Soc., 74, 5052, 1952.

[23] S. Chaberek and A.E. Martell, J. Am. Chem. Soc., 77, $1477,1955$.

[24] R. Nayan and A.K. Dey, Indian J. Chem., 14-A, 892, 1976.

[25] M. Chandra, Transition Met. Chem., 8, 276-279, 1983.

[26] I.G. Sayce, Talanta, 15, 1397, 1968.

[27]I.G. Sayce, Talanta, 18, 653, 1971.

[28]I.G. Sayce and V.S. Sharma, Talanta, 19 831, 1972 .

[29] M.J. Hynes and M. O'Dowd, J. Chem. Soc. Dalton Trans., 1987. 